\title{
Influence of the Trochoidal Tool Path on Quality Surface of Groove Walls
}

\author{
Kamil Waszczuk ${ }^{1 *}$, Hubert Skowronek ${ }^{1}$, Paweł Karolczak ${ }^{1}$, \\ Maciej Kowalski', Marek Kołodziej ${ }^{1}$ \\ 1 Wroclaw University of Technology and Science, Faculty of Mechanical Engineering, Łukasiewicza 5, 50-370 \\ Wrocław, Poland \\ * Corresponding author's e-mail: kamil.waszczuk@pwr.edu.pl
}

\begin{abstract}
The article presents the results of machining materials in hardened state. In the paper, different trochoidal tool paths are compared with each other and with the conventional milling. The results of measurements show the relationship between tool path, roughness and waviness of grooves wall. The paper also presents pictures of grooves which were made. These results provide comparative material useful in the choice of the best milling strategy to the cutting process.
\end{abstract}

Keywords: trochoidal milling, tool path, slot milling, hard machining.

\section{INTRODUCTION}

In the milling technology, manufacturing machine parts of with increasing efficiency while maintaining correctly shaped dimensions is of the highest importance. One way to achieve it is to change the trajectory tool path from conventional milling to trochoidal milling. Cutting with lower tool arc of engagement enables manufacturing with higher cutting velocity, feed rate and depth of cut (Fig. 1).

Reducing tool arc of engagement reduce the cutting force that occurs during milling, which results in an increased process stability. The reduction of vibrations enables processing of brittle materials without risking their damage. Controlling the tool arc of engagement allows reducing the cutting forces up to $70 \%$, compared to conventional milling, where it is $180^{\circ}$ [8]. Lower energy demand determines the use of cheaper machine tools (with lower power consumption) or enables to use higher technological parameters. Larger depth of cut (usually up to 5-times greater than in conventional milling) leads to a fourfold increase in the machining efficiency, expressed in $\mathrm{cm}^{3} / \mathrm{min}$ [12]. A tool with a much smaller diameter (usually twice as small) is used to make the groove. This results in an easier removal of chips from the cutting point, and eventually prevents re-cutting of chips. The reduction of the tool arc of engagement (which is usually in the range of $8-60^{\circ}$ ) allows to improve the cooling conditions of the tool. The method allows shortening the working time of individual blades, thus extending the time of their stay outside the material. This results in effective cooling and increased tool durability. The process does not need to use a cooling and lubricating medium. This enables to reduce the costs connected with the use of liquid in the company. Another consequence is increased durability of the cutting edge by reducing thermal shocks caused by the use of coolant [9]. A more detailed description of trochoidal milling can be found in the article $[1,2,11,13]$.

\section{Quality surface of groove walls in trochoichidal milling process}

In the results of the research, contained in the reference [9], the analyzes showing the influ- 

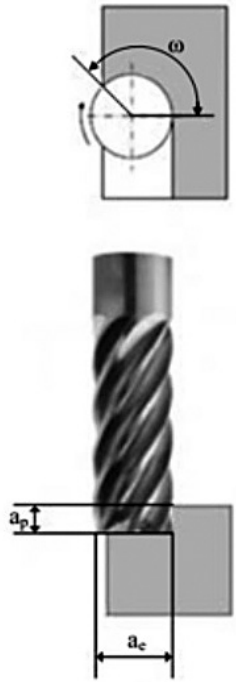

Conventional milling
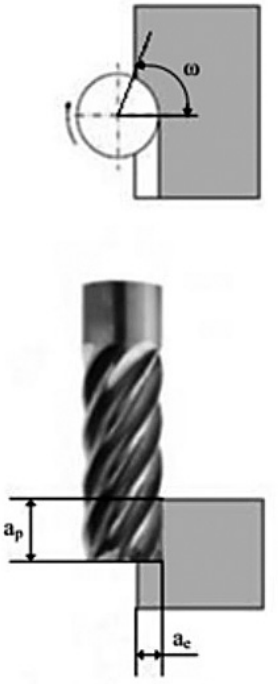

Trochoidal milling
Fig. 1. Comparison of the idea of conventional and trochoidal milling, where: $a_{p}$ - milling depth, $a_{e}-$ width of cut, $\omega-$ tool arc of engagement [6]

ence of the depth of milling $a_{p}$ and feed $f_{z}$ on the roughness Rz of the wall of the obtained groove were compiled. Trochoidal machining was performed using a type A path. Based on the observed results, it was found that along with the increase in feed, the $\mathrm{Rz}$ wall roughness value grows linearly. The increase in $\mathrm{Rz}$ roughness is strongly correlated with the increase in the depth of cutting $\left(a_{p}\right)$.

The research team led by the Parasad Patil from the University of Deakin in Australia studied the impact of trochoid parameters on the roughness $\mathrm{Ra}$ of the groove [5]. The milling was carried out using the A-type trochoidal tools path. On the basis of the test results, it can be stated that the groove roughness, when changing the extreme values of the parameters used in the tests, ranges from 2.4 to $3.2 \mu \mathrm{m}$. These changes are not significant compared to the possibility of increasing the temporary efficiency of the Qw process by up to $280 \%$.

On the basis of the analyzed literature in the field of surface quality $[3-7,10]$, it was found necessary to carry out studies showing the influence of the path type on the roughness and waviness of the surface obtained.

\section{RESEARCH METHODOLOGY}

The aim of the study was to determine the influence of the type of tool motion path on selected technological effects in trochoidal milling groove in hardened material. The investigated material was $145 \mathrm{Cr} 6$ (1.2063) steel in hardened state (58 $+/-2$ HRC). The monolith cemented carbide shank milling cutter (type: EC-H7 10-20C10CF-M72, see Figure 2) was given to our disposal by a representative of ISCAR Katowice. The tool has 7 flutes with different helix and variable pitch for chatter free operation. It was placed into hydraulic adapter HC 10 x 80 e 346958341080 produced by SECO.

The research was carried out on CNC machining centre Hermle C600 with Heidenhain iTNC530 driver. After the milling process, the surface roughness and waviness of walls of the
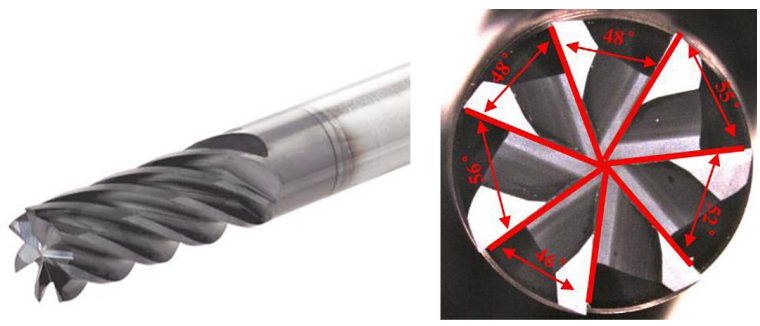

Fig. 2. Iscar milling tool - 7-flutes with different helix and variable pitch for trochoidal milling

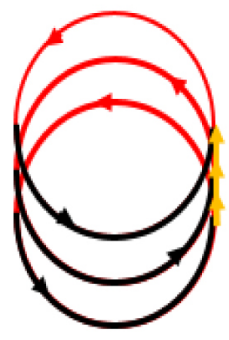

A- quasi-trochoid
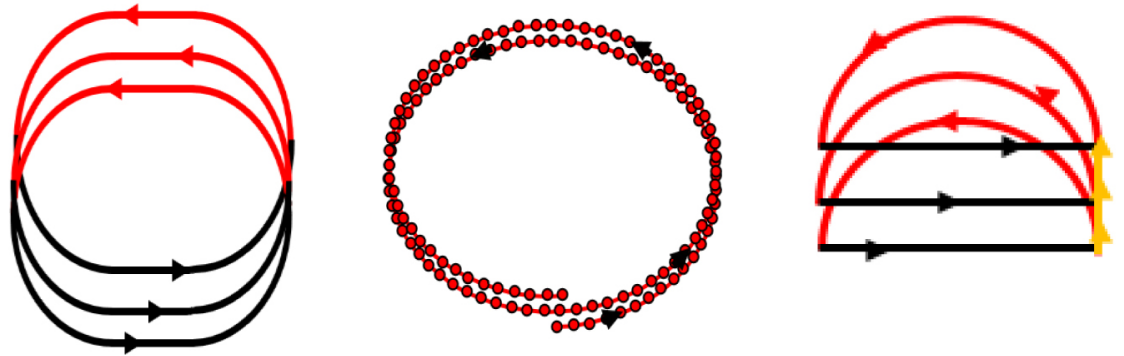

The path called:
B- stretched quasi- trochoid
D- semi-quasi-trochoid quasi-trochoid

Fig. 3. Paths used in trochoidal milling 
grooves were measured. In the research, Taylor Hobson Talysurf $120 \mathrm{~L}$ model was used.

The paths used in the research (Fig. 3), involved:

- A - quasi-trochoid: described by movement circle,

- B - stretched quasi-trochoid: described by arcs and straight lines,

- $\mathrm{C}$ - point by point quasi-trochoid: described by a short lines between numerous points,

- D - semi-quasi-trochoid: described by half circle and straight line.

Trochoidal milling was compared with the conventional machining - defined as milling on full width of cutter. In the research, variable cutting parameters were: velocity cutting and feed per tooth. Minimum and maximum values were selected based on the tool manufacturers recommendations for cutting harded steel (50-60 HRC): $\min \mathrm{v}_{\mathrm{c}}=100 \mathrm{~m} / \mathrm{min}, \mathrm{f}_{\mathrm{z}}=0.03 \mathrm{~mm}$; $\max$ : $\mathrm{v}_{\mathrm{c}}=150 \mathrm{~m} / \mathrm{min}, \mathrm{f}_{\mathrm{z}}=0,06 \mathrm{~mm}$. In the research, stable parameters for trochoidal milling were: step over $\mathrm{w}=0.6 \mathrm{~mm}$, depth of cut $\mathrm{a}_{\mathrm{p}}=10 \mathrm{~mm}$. In the conventional milling (path/method called G), variable cutting parameters were: velocity cutting and feed per tooth also recommended for tool manufacturers for the hardened steel: $\min$ $\mathrm{v}_{\mathrm{c}}=60 \mathrm{~m} / \mathrm{min}, \mathrm{f}_{\mathrm{z}}=0.02 \mathrm{~mm} ; \max : \mathrm{v}_{\mathrm{c}}=90 \mathrm{~m} /$ $\min , \mathrm{f}_{\mathrm{z}}=0.04 \mathrm{~mm}$. The remaining cutting parameters were set as constant: depth of cut $\mathrm{a}_{\mathrm{p}}=2 \mathrm{~mm}$ width of cut $\mathrm{a}_{\mathrm{e}}=10 \mathrm{~mm}$.

For all types of milling, the constant parameters were:

- length of cutting path $\mathrm{LS}=50 \mathrm{~mm}$,

- depth of cutting path DS $=10 \mathrm{~mm}$,

- width of groove $\mathrm{WS}=28 \mathrm{~mm}$,

- type of cooling: air influence for nozzle $10 \mathrm{bar}$ (145 psi).

\section{RESULTS}

Figure 4 shows the results of measurements of the surface roughness $\mathrm{Ra}$ and of grooves walls. The lowest roughness values were obtained during conventional milling. On average, they are lower by about $50 \%$, compared to the trochoidal milling. The lower Ra values during conventional milling result from the way the cutting edges cuts and the more rigid tool guidance - only on one axis.

Additionally, in the conventional milling, in order for the tool to make a groove with a depth of $10 \mathrm{~mm}$, it must delve 5 times, so that in subsequent passes the tool smoothens the side walls.

By comparing the trochoidal paths, it can be observed that milling using a B path allows to obtain the lowest $\mathrm{Ra}$ values. It is related to the trochoidal stroke which occurs on both side of the groove walls, which makes them smoother in subsequent passes. A significant increase in the roughness of the side walls after milling using the type D path is caused by sudden changes in the direction of the tool movements. The tool starts the cycle after circular interpolation and then stops to follow the straight line. Sudden changes in the direction of the movements transfer into an increase in the roughness value.

The second parameter selected for the analysis was waviness Wa parameter. Figure 5 shows the results of measurements of the surface waviness Wa and of grooves walls. Similarly to the roughness results, the surface waviness is lowest during the conventional milling. The values for waviness during conventional milling are lower by about $50 \%$ compared to the B-type trochoidal path and nearly $80 \%$ lower than during Trochoidal C-type process-

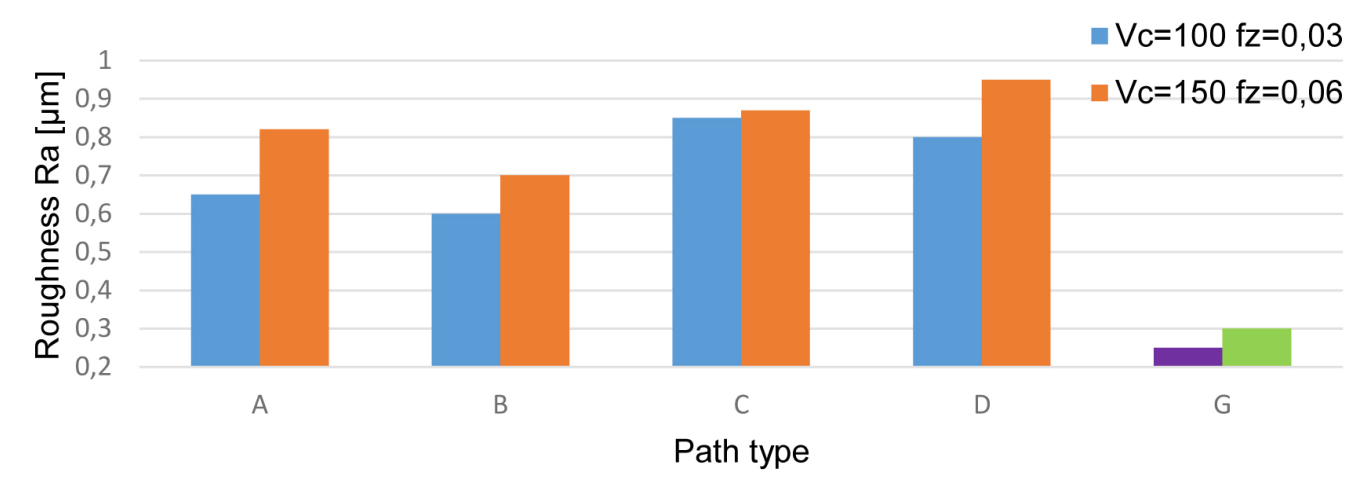

Fig. 4. Influence of path type on roughness parameter Ra of grooves walls 


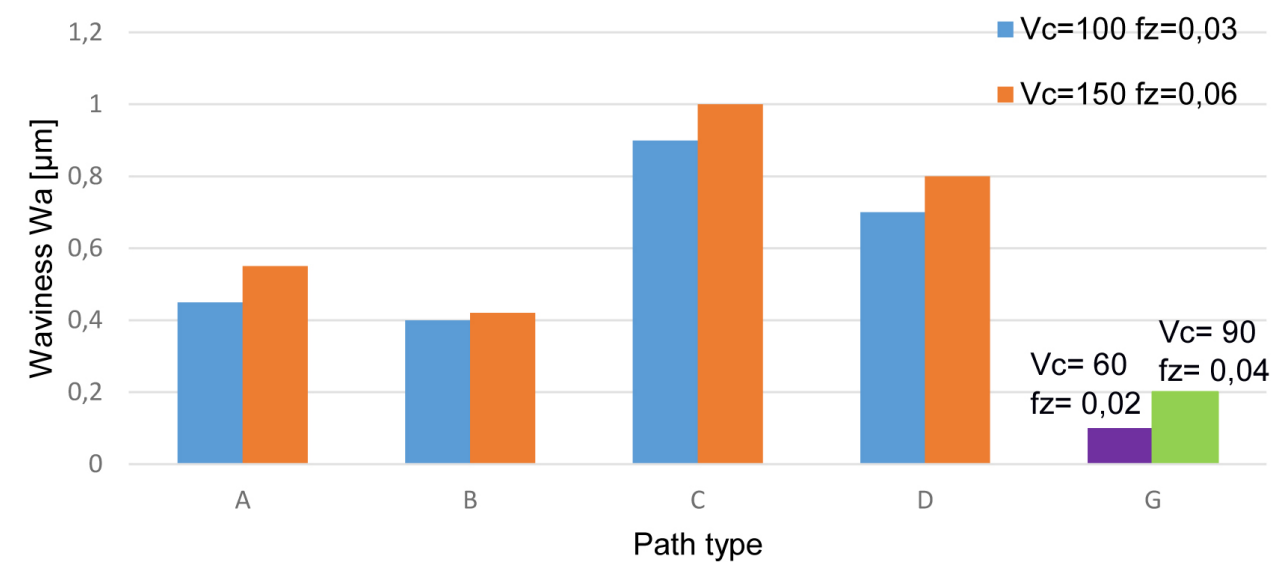

Fig. 5. Influence of path type on waviness parameter Wa of grooves walls

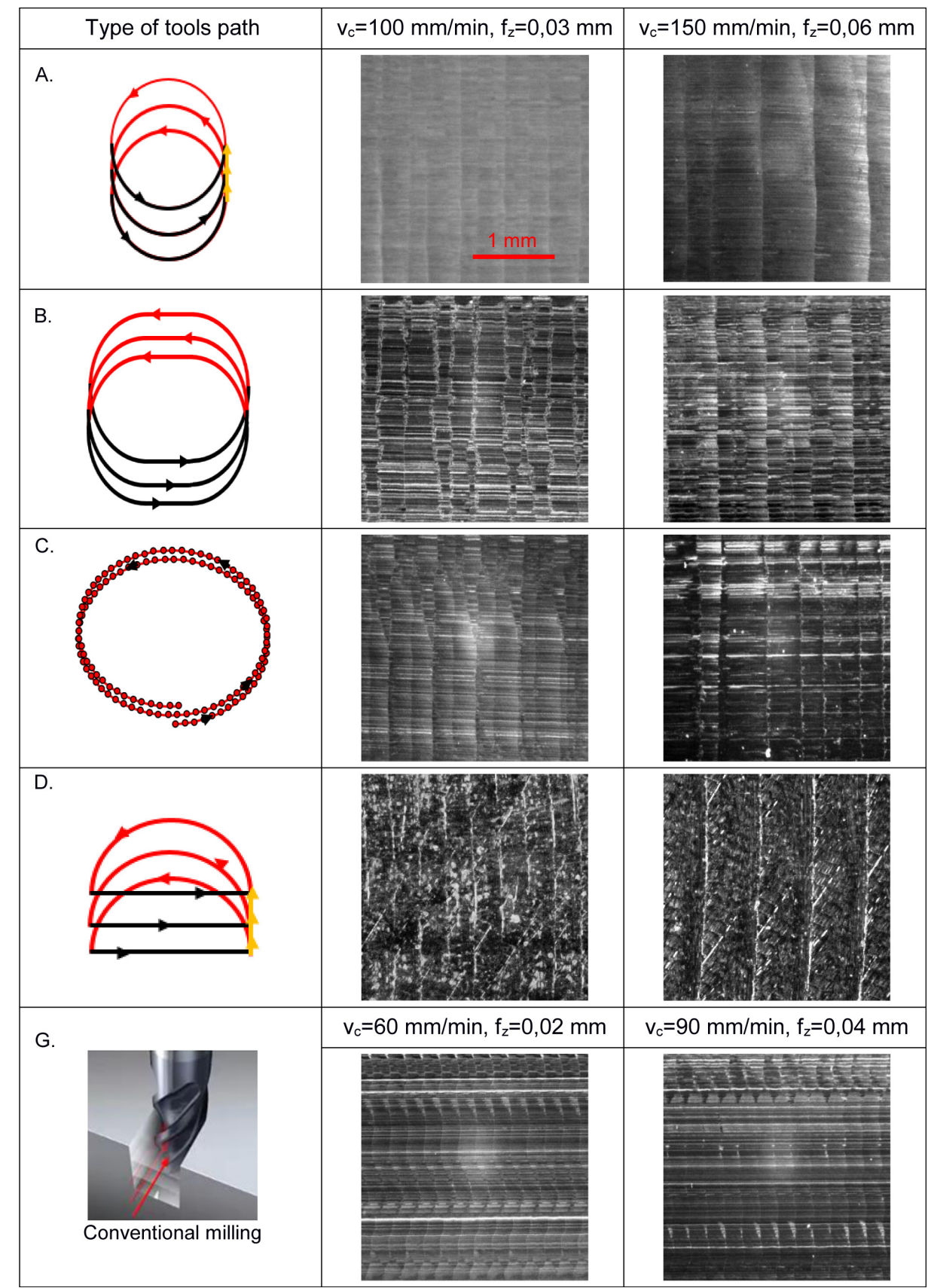

Fig. 6. Photos of groove walls with variable machining parameters and various trochoidal tool paths 
ing. Among the trochoidal pathways analysed, the highest waviness values were obtained during the trimming using a Trochoidal C-type chute. The movement between points forming the path transfers into a sudden increase in speed and deceleration in the $\mathrm{X}$ and $\mathrm{Y}$ axes of milling machine, which negatively affects the surface waviness.

Figure 6 contains a photographic analysis of the created grooves. The studies used a 60x zoom of the lens. The visual differences, which were observed, can have a significant impact on the classification of trochoidal milling, known as finishing processing [5]. The visual aspects of finished products can have important features for the end recipients, i.e. consumers. During the trochoidal milling with circular interpolation (type A), circular-linear (type B) and offset point by point, the view of side walls of the groove were very similar. Using the Trochoidal path type D on the walls of the obtained groove one can notice characteristic slanting incisions. They result from dynamic tool stop and a sudden change of the cutting direction.

\section{CONCLUSIONS}

Trochoidal milling is one of the alternative methods of processing materials in hardened condition. Trochoidal milling allows machining with a much higher volume of process efficiency. The most important conclusions include:

1. The path type has a more effect on the waviness than on the surface roughness. This is due to the fact that the quality of the surface is more affected by the type of trajectory of the tool path, not the technological parameters.

2. The increase in the value of technological parameters (with $\mathrm{v}_{\mathrm{c}}=100 \mathrm{~m} / \mathrm{min}, \mathrm{f}_{\mathrm{z}}=0.03 \mathrm{~mm}$ to $\left.\mathrm{v}_{\mathrm{c}}=150 \mathrm{~m} / \mathrm{min}, \mathrm{f}_{\mathrm{z}}=0.06 \mathrm{~mm}\right)$ slightly affects the increase of Ra and Wa parameters for trochoidal paths, in particular the roughness parameter for type $C$ path and waviness for type B path. This can be important in planning the production process, because any increase in technological parameters while maintaining the surface quality meaning transfers into a reduction in manufacturing costs.

\section{REFERENCES}

1. Dąbrowski L. Czy HSM wyprze EDM? Świat Obrabiarek, 11-12, 2009, 14-18.

2. Jóźwik J., Kobyłka M. Badanie wpływu parametrów geometrycznych kieszeni prostokątnej oraz warunków realizacji procesu skrawania na drgania podczas frezowania trochoidalnego. Postępy Nauki i Techniki, 8, 2011, 37-44.

3. Mestry T., Raut N. Optimization of cutting parameters in high speed trochoidal machining, 4(4), 2017, 241-247.

4. Oliaei S.N.B., Karpat Y. Experimental investigations on micro milling of stavax stainless steel. Elsevier, 6th CIRP International Conference on High Performance Cutting, HPC2014, Procedia CIRP, 14, 2014, 377-382.

5. Patil P., Polishetty A., Goldberg M., Littlefair Junior G.: Slot machining of Ti6Al4V with trochoidal milling technique. Journal of Machine Engineering, 14, 2014, 42-54.

6. Pleta A., Mears L. Cutting force investigation of trochoidal milling in nickel-based superalloy. Elsevier, 44th Proceedings of the North American Manufacturing, 5, 2016, 1348-1356.

7. Polishetty A., Goldberg M., Littlefair G., Puttaraju M., Patil P., Kalra A. A preliminary assessment of machinability of titanium alloy Ti6Al4V during thin wall machining using trochoidal milling. Elsevier. Procedia Engineering, 97, 2014, 357-364.

8. Szaloki I., Csuka S., Sipos S., Csesznok S. Can trochoidal milling be ideal? International Manufacturing Conference. Budapest. Hungary. November, 2012, 14-16.

9. Szaloki I., Csuka S., Sipos S. New test results in cycloid-forming trochoidal milling. Acta Polytechnica Hungarica, 11, 2014, 215-228.

10. Vogtel P., Klocke F., Lung D. High performance machining of profiled slots in nickel-based-superalloys. Elsevier, 6th CIRP International Conference on High Performance Cutting, HPC2014, Procedia CIRP 14, 2014, 54-59.

11. Waszczuk K., Karolczak P., Wiśniewska M., Kowalski M. Influence of the path type on selected technological effects in the trochoidal milling. Advances in Science and Technology Research Journal, 11(1), 2017, 147-153.

12. Waszczuk K., Socha K. Frezowanie trochoidalne - sposób obróbki ubytkowej materiałów w stanie utwardzonym. In: Interdyscyplinarność badań naukowych. Oficyna Wydawnicza Politechniki Wrocławskiej, 2015, 257-256.

13. Zalewski A. Obróbka trochoidalna na frezarkach CNC. Mechanik, 4, 2007, 303-304. 